\title{
The Perceived Oral Health Status, Practices, Knowledge and Periodontal Status of Pregnant Women in a Maternity Hospital in Trinidad
}

\section{Reisha Rafeek*, Visha Ramsaroop, Ramaa Balkaran, Anne Kowlessar, Arlana Bissoon, Christine Royer and Risa Yuk Low}

School of Dentistry, Faculty of Medical Sciences, The University of the West Indies, St. Augustine, Trinidad and Tobago

*Corresponding Author: Reisha Rafeek, School of Dentistry, Faculty of Medical Sciences, The University of the West Indies, St. Augustine, Trinidad and Tobago.
Received: October 05, 2020

Published: October 28, 2020

(C) All rights are reserved by Reisha Rafeek., et al.

\begin{abstract}
Background: The aim of this study is to report the oral health status, practices, knowledge and periodontal status of pregnant women in a maternity hospital in Trinidad.

Methods: A convenience sample of pregnant women who attended a maternity hospital was recruited. Data were collected using a self-administered questionnaire which included frequency and reason for dental attendance, perceived oral health status and oral health knowledge and practices. Oral health examinations took place at the University of the West Indies (UWI), School of Dentistry including the Basic Periodontal Examination (BPE). Data were analyzed using SPSS version 24.0 in which descriptive analysis and Chi-square tests were performed.

Results: 161 pregnant women participated. Nearly 60\% rated their oral health as average or good. Almost half (46.0\%) stated safety concerns with dental treatment during pregnancy prevented them from seeking care and 73.3\% did not believe that a mother's poor oral health could contribute to low birth weight (LBW) babies. The majority (91.9\%) did not attend the dentist routinely and nearly $60 \%$ had some form of periodontitis, mild (34.2\%) or moderate to severe (25.2\%). Significant associations were found between level of education and brushing ( $\mathrm{p}<0.05)$, age and smoking $(\mathrm{p}<0.05)$, BPE and age $(\mathrm{p}<0.05)$ and BPE and ethnicity $(\mathrm{p}<0.05)$.

Conclusions: There are important gaps and misconceptions in oral health knowledge and practices of pregnant women and the prevalence of periodontitis was found to be high and related to age and ethnicity.
\end{abstract}

Keywords: Pregnancy; Oral Health; Periodontal Health; Women; BPE

\section{Abbreviations}

UWI: University of the West Indies; BPE: Basic Periodontal Examination; LBW: Low Birth Weight

\section{Introduction}

Oral health can affect pregnancy. For instance, the effects of the hormonal changes that occur during pregnancy on the oral tissues have been well documented over time. The physiological state of pregnancy has been associated with gingival changes which are comparable to changes in vaginal and other mucosal tissues during gestation [1]. The microvasculature of the gingiva changes during pregnancy due to increasing levels of progesterone [2]. Additionally, the dental hard tissues such as enamel are susceptible to increased gastric acid exposure due to morning sickness and increased vomiting especially in the first trimester among pregnant women [1].

Gingivitis is common in the general adult population and the prevalence of periodontitis is reported to be $10-15 \%$ [3]. The prevalence of oral disease in pregnancy is about 44\% $[1,4]$. There is no prevalence data on periodontal disease in the general popu- 
The Perceived Oral Health Status, Practices, Knowledge and Periodontal Status of Pregnant Women in a Maternity Hospital in Trinidad

lation in Trinidad and Tobago but it has been reported to be over $67 \%$ in a diabetic population in that country [5].

There is an association between gum disease (gingivitis and periodontitis) and adverse pregnancy outcomes such as low birth weight and premature births [6,7]. However, many pregnant women are unaware of this $[8,9]$ and do not often seek dental treatment during pregnancy [10]. It has therefore been recognized that maintaining oral health during pregnancy is an important public health issue worldwide and as such it is now recommended that all women should receive a comprehensive oral health evaluation and risk assessment during pregnancy [11,12]. Pregnancy has been described as a powerful "teachable moment" for the promotion of health as expectant mothers are especially keen on their baby being born healthy. Dentists can therefore seize the opportunity to fulfill their roles as educators and health promoters during this physiological state [13].

The oral health status, practices, knowledge and periodontal status of pregnant women has not to the best of our knowledge been studied before in Trinidad and Tobago and this study aims to provide epidemiological data on this subject with an aim to guiding oral health promotion programmes, as none exists for expectant mothers. This will assist in the delivery of preventive care to expectant mothers and potentially improve pregnancy outcomes in Trinidad and Tobago and the wider Caribbean region. The aim of this study is to report the oral health status, practices, knowledge and periodontal status of pregnant women in a maternity hospital in Trinidad.

\section{Materials and Methods}

A convenience sample of pregnant women who attended the antenatal clinic in Mount Hope maternity clinic during the period of data collection (January to December 2018) was undertaken. The Mount Hope Maternity hospital is accessible to the public without charge like other public-health care facilities in the country. All women who were pregnant and sought health care at that maternity hospital were invited to participate in a descriptive oral health survey involving a self-administered questionnaire and a simple oral health examination at the University of the West Indies (UWI), School of Dentistry clinic, Mt. Hope. Exclusion criteria were males and women who were not pregnant at the time of examination.

Demographic data such as age group, self-reported ethnicity, highest qualification achieved and employment status, medical and dental history, frequency, reason for dental attendance were determined from a self-administered questionnaire. The patients' perceived oral health status, knowledge and practices were also determined in the self-administered questionnaire, which was a previously administered questionnaire [8] modified for our population. The questionnaire was pre-tested to ensure clarity and understanding. Feedback was obtained and the questionnaire modified as needed.

Oral examinations were performed by two examiners who had previously been trained in the use of the assessment criteria which was agreed upon by the two participating dentists and were calibrated. Examinations were conducted in an examination room at the Mount Hope Maternity Hospital. Plaque score and BPE scores were recorded with the patients sitting on a chair with their heads tilted backwards and with the aid of the overhead light as well as an additional examination light. A dental mirror and a BPE probe were used to record the presence of plaques as well to identify presence of bleeding and to determine pocket depths. As the examinations were not conducted in a dental setting, teeth were not dried with an air water syringe prior to examination. Examination involved extra-oral assessment, the patients' visible plaque score using the plaque index of Silness and Löe and the Basic Periodontal Examination (BPE), to determine the periodontal health status.

Guidelines of the Silness and Löe plaque index were followed using the criteria of using 4 surfaces of the 6 selected teeth. There was no substitution for any missing tooth, wisdom teeth were excluded. All surfaces were selected, the scores from the four areas of the tooth were added and divided by four in order to obtain the plaque index [14] for the tooth; the following scores were used: 0 No plaque; $1 \mathrm{~A}$ film of plaque adhering to the free gingival margin and adjacent area of the tooth, which cannot be seen with the naked eye, only by using disclosing solution or by using probe; 2 Moderate accumulation of deposits within the gingival pocket, on the gingival margin and/or adjacent tooth surface, which can be seen with the naked eye; 3 Abundance of soft matter within the gingival pocket and/or on the tooth and gingival margin. The Basic Periodontal Examination (BPE), also known as Periodontal Screening and Recording (PSR) Index, is a screening tool for periodontal treatment needs, which identifies the presence or absence of disease [15]. BPE criteria and coding were based on that described by Corbet 2012. Firstly, the mouth was divided into six sextants, only sextants with two or more teeth present were used, all third molars and root remnants were excluded and the highest score was recorded for that sextant. The BPE score was determined us- 
ing a World Health Organisation/Community Periodontal Index of Treatment Needs probe periodontal probe [16]. The probe was used to detect bleeding and loss of attachment around the teeth, as well as bone loss between the roots of the teeth (furcation involvement). The presence of recession was recorded and this was measured from cemento- enamel junction to the free gingival margin. All patients who had any conditions which required urgent care were identified, the patients were informed and offered treatment at the UWI dental school emergency clinic and polyclinic.

At the end of the period of data collection, the sample size was 161 participants. Some pregnant mothers did not wish to participate in the study and 10 women were no longer pregnant at the time of presentation for oral examination and therefore their questionnaires were excluded from the final data analysis. A power calculation was not undertaken however the sample size was considered amenable to statistical analyses. No biases regarding the selection of subjects were anticipated and the sample was representative of the population.

Data were analyzed using SPSS version 24.0 in which descriptive analysis, including cross tabulations, were performed. Inference on the cross tabulations was performed, using chi-square tests to test for general associations. The level of significance used was 0.05 . Ethical approval was obtained by the University of the West Indies Research Ethics Committee (CEC 242/07/17) and written, informed consent was obtained from each patient prior to the oral health survey. All the materials and methods that are used to complete the study should be mentioned.

\section{Results}

The socio- demographic and obstetric profiles of the mothers are presented in table 1. Over three-quarters (79.5\%) of pregnant women in this study were between the ages 26 to 45 . Over a third (34.8\%) were of Afro- Caribbean descent, 27.3\% were Indo-Caribbean and $36.0 \%$ were mixed. More than half (57.1\%) had attended high school, $23.6 \%$ had attended University and over half (58.1\%) of the participants were employed. The majority $(82.6 \%)$ stated that it was not their first pregnancy and 50.9\% were in their 2nd trimester of pregnancy.
The perceived oral health status of the mothers is presented in table 2. Over two-thirds of the respondents in this study (69.1\%) rated their oral health as fair or average. The majority (85.1\%) reported having at least one or more problems with their oral health with approximately two thirds (65.2\%) reported having cavities and almost half (47.2\%) said that they were experiencing sensitivity. Over two-thirds (67.5\%) of the respondents indicated that their oral health problems sometimes affected their ability to eat as well as their overall general health.

\begin{tabular}{|l|c|}
\hline Characteristics & Frequency (\%) \\
\hline Age & \\
$15-25$ & $32(19.9)$ \\
$26-35$ & $98(60.9)$ \\
$36-45$ & $30(18.6)$ \\
46 and over & $1(0.6)$ \\
\hline Ethnicity & \\
Afro-Caribbean & $56(34.8)$ \\
Indo-Caribbean & $44(27.3)$ \\
Chinese & $1(0.6)$ \\
Mixed & $58(36)$ \\
Caucasian & $1(0.6)$ \\
Other & $1(0.6)$ \\
\hline Highest qualification achieved & $16(9.9)$ \\
Primary School & $92(57.1)$ \\
High school Education & $38(23.6)$ \\
University & $15(9.3)$ \\
Vocational training & \\
\hline Current employment status & $67(41.9)$ \\
Unemployed & $16(10)$ \\
Employed part-time & $76(47.5)$ \\
Employed-full time & $25(15.7)$ \\
\hline Period of gestation & $51(50.9)$ \\
$1^{\text {st }}$ & $133(83.3)$ \\
$2^{\text {nd }}$ & \\
$3^{\text {rd }}$ & \\
\hline Is this your first pregnancy? & \\
Yes & \\
No & \\
\hline
\end{tabular}

Table 1: Socio-demographic information and obstetric characteristics of participants $(n=161)$. 


\begin{tabular}{|l|l|}
\hline Variables & $\begin{array}{c}\text { Frequency } \\
\text { (\%) }\end{array}$ \\
\hline Oral health status & $7(4.4)$ \\
Excellent & $25(15.7)$ \\
Good & $67(42.1)$ \\
Average & $43(27.0)$ \\
Fair & $17(10.7)$ \\
Poor & \\
\hline Self-reported oral health problems & $24(14.9)$ \\
None & $44(27.3)$ \\
One problem & $93(57.8)$ \\
Two or more problems & \\
\hline Type of oral health problems & $60(37.3)$ \\
Bleeding gums & $55(34.2)$ \\
Toothache & $16(9.9)$ \\
Loose teeth & $105(65.2)$ \\
Cavities & $76(47.2)$ \\
Sensitivity & $41(25.5)$ \\
\hline Teeth don't look right & \\
\hline Dental problems affected what to \\
eat and overall health in general \\
Often & $19(11.9)$ \\
Sometimes & $108(67.5)$ \\
Never & $33(20.6)$ \\
\hline Importance of oral health when \\
compared to overall health \\
Not important & $0(0)$ \\
Neutral & $111(68.9)$ \\
Important & \\
Extremely Important & \\
\hline
\end{tabular}

Table 2: Perceived oral health status of pregnant women $(\mathrm{n}=161)$.
The oral health knowledge of the mothers is presented in table 3. The majority of respondents in this study (98.1\%) thought that routine visits to the dentist could help keep teeth and gums healthy. Despite this, (37.3\%) thought that dental care should be avoided during pregnancy unless it was an emergency. The majority $(80.4 \%)$ felt that cavities could not be spread form the mother to the baby's mouth and $73.3 \%$ did not believe that a mother's poor oral health could contribute to low birth weight (LBW) babies. Another important finding of this study was that $8.1 \%$ of the expectant mothers were smokers.

The oral health practices of the mothers are presented in table 4. The majority of women (87.6\%) did not have a dentist, most $(91.9 \%)$ did not attend the dentist routinely and the most common reason for the last dental visit was pain (35.4\%). Almost half $(46.0 \%)$ of the participants said concerns regarding safety of dental treatment during pregnancy would prevent them from seeking care and more than half $(54.7 \%)$ said the cost of dental treatment would act as a barrier to dental care.

Over a quarter of pregnant mothers (25.5\%) had a BPE of 4 which meant moderate or advanced periodontitis and $34.2 \%$ had a BPE code of 3, which meant mild periodontitis. More than onethird of pregnant mothers (37.2\%) had gingivitis (BPE codes 1 and 2) and only $3.1 \%$ had BPE code 0 meaning healthy periodontium.

There were no associations with ethnicity, education or level of employment and oral health knowledge $(p>0.05)$ and when investigating oral health practices, no associations were observed with ethnicity, level of employment or when last the women visited the dentist versus brushing, flossing and use of mouthwash ( $p>0.05)$. However, there were significant associations found between level of education and brushing $(\mathrm{p}<0.05)$ (Table 5), between when last the women visited the dentist and their perceived oral health status $(\mathrm{p}<0.05)$ and also between age and the use of mouthwash ( $p$ $<0.05$ ) and smoking $(\mathrm{p}<0.05)$ (Table 6). With respect to the periodontal status of the women there was a significant association between BPE and age $(\mathrm{p}<0.05)$ (Table 6) and BPE and ethnicity (p $<0.05$ ) but no association was observed for education or level of employment with BPE (Table 7).

\begin{tabular}{|c|c|c|}
\hline Item content & True $\%$ & False \% \\
\hline Flossing should be done daily to clean in between teeth. & 97.5 & 2.5 \\
\hline Routine dental visits help keep teeth and gums healthy. & 98.1 & 1.9 \\
\hline Pregnant women should avoid dental treatment unless it's an emergency. & 37.3 & 62.7 \\
\hline Dental decay or cavities can spread from the mother to the baby's mouth. & 19.6 & 80.4 \\
\hline A mother's poor oral hygiene may contribute to low birth weight. & 26.7 & 73.3 \\
\hline The first tooth usually appears at around 6 months of age. & 78.3 & 21.7 \\
\hline Sleeping with a bottle containing formula could cause holes on a baby's teeth. & 67.7 & 32.3 \\
\hline Cavities on baby teeth are $\mathrm{OK}$ because they will fall out anyway. & 11.2 & 88.8 \\
\hline
\end{tabular}

Table 3: Oral health knowledge: percentage of participant responses by individual survey items. 


\begin{tabular}{|c|c|}
\hline Variables & Frequency (\%) \\
\hline \multicolumn{2}{|l|}{ Do you have a dentist currently? } \\
\hline Yes & $20(12.4)$ \\
\hline No & $141(87.6)$ \\
\hline \multicolumn{2}{|l|}{ Do you attend the dentist for routine care? } \\
\hline Yes & $13(8.1)$ \\
\hline No & $148(91.9)$ \\
\hline \multicolumn{2}{|l|}{ Do you attend the dentist only when you have a problem? } \\
\hline Yes & $119(74.8)$ \\
\hline No & $39(24.5)$ \\
\hline \multicolumn{2}{|l|}{ When was the last time you saw a dentist? } \\
\hline$<6$ months & $10(6.2)$ \\
\hline 6 to $<12$ months & $18(11.2)$ \\
\hline $1 \mathrm{yr}$ to $<2$ years & $33(20.5)$ \\
\hline 2 yrs to $<5$ years & $42(26.1)$ \\
\hline$>5$ years & $33(20.5)$ \\
\hline Never visited & $25(15.5)$ \\
\hline \multicolumn{2}{|l|}{ What was the reason for your last dental visit? } \\
\hline Pain & $57(35.4)$ \\
\hline Filling & $42(26.1)$ \\
\hline Cleaning & $31(19.3)$ \\
\hline Checkup & $17(10.6)$ \\
\hline Other & $22(13.7)$ \\
\hline \multicolumn{2}{|l|}{ What would prevent you from seeking dental treatment, if any? } \\
\hline Safety concerns regarding treatment during pregnancy & $74(46)$ \\
\hline Dental costs & $88(54.7)$ \\
\hline Time constraint & $31(19.3)$ \\
\hline Oral health not seen as a priority & $9(5.6)$ \\
\hline Advised by antenatal care providers not to seek treatment & $15(9.3)$ \\
\hline \multicolumn{2}{|l|}{ How often do you brush your teeth? } \\
\hline A few times a week & $2(1.2)$ \\
\hline Once a day & $34(21.1)$ \\
\hline Twice a day & $104(64.6)$ \\
\hline More than twice a day & $21(13)$ \\
\hline \multicolumn{2}{|l|}{$\begin{array}{l}\text { What oral hygiene products do you use regularly? (Please tick } \\
\text { appropriate answer or answers) }\end{array}$} \\
\hline Fluoride toothpaste & $147(91.9)$ \\
\hline Mouthwash & $77(48.1)$ \\
\hline Dental floss & $47(29.4)$ \\
\hline Sugar free gum & $5(3.1)$ \\
\hline
\end{tabular}

Table 4: Oral health practices $(n=161)$. 


\begin{tabular}{|c|c|c|c|c|c|c|}
\hline \multicolumn{7}{|l|}{ Education } \\
\hline $\begin{array}{l}\text { How often teeth were } \\
\text { brushed }\end{array}$ & Weekly \% & Once daily \% & $\begin{array}{c}\text { Twice daily } \\
\%\end{array}$ & $\begin{array}{c}\text { More than } \\
\text { twice daily \% }\end{array}$ & $\begin{array}{l}\text { Chi-Squared } \\
\left(\chi^{2}\right)\end{array}$ & $p$-value \\
\hline Primary school & 1 & 2 & 12 & 1 & & \\
\hline High school & 0 & 19 & 62 & 11 & & \\
\hline Vocational training & 1 & 0 & 11 & 3 & & \\
\hline University & 0 & 13 & 19 & 6 & $18.458^{\mathrm{a}}$ & 0.03 \\
\hline Use of mouthwash & No $\%$ & Yes \% & & & & \\
\hline Primary school & 10 & 6 & & & & \\
\hline High school & 46 & 45 & & & & \\
\hline Vocational training & 9 & 6 & & & & \\
\hline University & 18 & 20 & & & $1.493^{\mathrm{a}}$ & 0.684 \\
\hline Use of Floss & No $\%$ & Yes $\%$ & & & & \\
\hline Primary school & 14 & 2 & & & & \\
\hline High school & 68 & 23 & & & & \\
\hline Vocational training & 10 & 5 & & & & \\
\hline University & 21 & 17 & & & $7.369^{\mathrm{a}}$ & 0.061 \\
\hline
\end{tabular}

Table 5: Dental hygiene practices of women versus education achieved.

Values are statistically significant $(\mathrm{p}<0.05)$.

\begin{tabular}{|c|c|c|c|c|c|c|c|}
\hline \multirow{2}{*}{$15-25$} & & \multicolumn{4}{|c|}{ Age } & & \multirow[b]{2}{*}{ p-value } \\
\hline & & \multirow{2}{*}{$\frac{26-35}{1}$} & \multirow{2}{*}{$36-45$} & \multirow{2}{*}{$\begin{array}{c}46 \text { and } \\
\text { over }\end{array}$} & \multirow{2}{*}{$\begin{array}{c}\begin{array}{c}\text { Chi-Squared } \\
\left(\chi^{2}\right)\end{array} \\
0 \\
\end{array}$} & & \\
\hline 1 & 3 & & & & & & \\
\hline 6 & 5 & 0 & & & 0 & & \\
\hline & 36 & 5 & & & 0 & & \\
\hline 8 & 33 & 10 & & & 0 & & \\
\hline $\begin{array}{l}12 \\
5\end{array}$ & 21 & 14 & & & 1 & & \\
\hline \multicolumn{2}{|l|}{32} & 98 & 30 & & 1 & $22.777^{a}$ & 0.030 \\
\hline \multirow[t]{2}{*}{ Mouthwash } & Yes & 9 & 55 & 13 & 0 & & \\
\hline & No & 23 & 42 & 17 & 1 & & \\
\hline \multicolumn{2}{|l|}{ Total } & 32 & 97 & 30 & 1 & $9.189^{\mathrm{a}}$ & 0.027 \\
\hline \multirow[t]{2}{*}{ Smoking } & Yes & 3 & 6 & 3 & 1 & & \\
\hline & No & 28 & 90 & 27 & 0 & & \\
\hline \multicolumn{2}{|l|}{ Total } & 31 & 97 & 30 & 1 & $11.862^{\mathrm{a}}$ & 0.008 \\
\hline
\end{tabular}

Table 6: Age versus BPE, use of mouthwash and smoking. Values are statistically significant $(\mathrm{p}<0.05)$. 


\begin{tabular}{|c|c|c|c|c|c|c|c|c|c|}
\hline \multirow{2}{*}{\multicolumn{2}{|c|}{ Afro-Caribbean }} & \multicolumn{6}{|c|}{ Ethnicity } & & \multirow{3}{*}{ p-value } \\
\hline & & \multirow{2}{*}{\begin{tabular}{|c}
$\begin{array}{c}\text { Indo-Carib- } \\
\text { bean }\end{array}$ \\
1 \\
\end{tabular}} & \multirow{2}{*}{$\begin{array}{c}\text { Chinese } \\
3 \\
\end{array}$} & \multirow{2}{*}{$\begin{array}{c}\text { Mixed } \\
0\end{array}$} & \multirow{2}{*}{$\begin{array}{c}\text { Caucasian } \\
1 \\
\end{array}$} & \multirow{2}{*}{$\begin{array}{c}\text { Other } \\
0 \\
\end{array}$} & \multirow{2}{*}{$\begin{array}{c}\begin{array}{c}\text { Chi-Squared } \\
\left(\chi^{2}\right)\end{array} \\
0\end{array}$} & & \\
\hline \multirow{5}{*}{ BPE } & 0 & & & & & & & & \\
\hline & 1 & 5 & 0 & 1 & 4 & 0 & 1 & & \\
\hline & 2 & 15 & 13 & 0 & 20 & 1 & 0 & & \\
\hline & 3 & 21 & 16 & 0 & 18 & 0 & 0 & & \\
\hline & 4 & 14 & 12 & 0 & 15 & 0 & 0 & & \\
\hline \multicolumn{2}{|l|}{ Total } & 56 & 44 & 1 & 58 & 1 & 1 & $36.593^{\mathrm{a}}$ & 0.013 \\
\hline \multirow{2}{*}{\multicolumn{2}{|c|}{ Primary school }} & \multicolumn{6}{|c|}{ Level of qualification } & & \multirow[b]{2}{*}{ p-value } \\
\hline & & High school & $\begin{array}{c}\text { Vocational } \\
\text { training }\end{array}$ & University & Total & & $\begin{array}{c}\text { Chi-Squared } \\
\left(\chi^{2}\right)\end{array}$ & & \\
\hline \multirow{5}{*}{ BPE } & 0 & 0 & 2 & 2 & 1 & 5 & & & \\
\hline & 1 & 0 & 5 & 5 & 1 & 11 & & & \\
\hline & 2 & 3 & 33 & 11 & 2 & 49 & & & \\
\hline & 3 & 6 & 29 & 14 & 6 & 55 & & & \\
\hline & 4 & 7 & 23 & 6 & 5 & 41 & & & \\
\hline \multicolumn{2}{|l|}{ Total } & 16 & 92 & 38 & 15 & 161 & & $12.938^{\mathrm{a}}$ & 0.374 \\
\hline \multirow{2}{*}{\multicolumn{2}{|c|}{ Un-employed }} & \multicolumn{6}{|c|}{ Level of employment } & & \multirow[b]{2}{*}{ p-value } \\
\hline & & $\begin{array}{l}\text { Part-time } \\
\text { employed }\end{array}$ & $\begin{array}{l}\text { Full -time } \\
\text { employed }\end{array}$ & $\begin{array}{l}\text { Self-em- } \\
\text { ployed }\end{array}$ & Total & & $\begin{array}{c}\text { Chi-Squared } \\
\left(\chi^{2}\right)\end{array}$ & & \\
\hline \multirow{5}{*}{ BPE } & 0 & 3 & 1 & 1 & 0 & 5 & & & \\
\hline & 1 & 7 & 1 & 3 & 0 & 11 & & & \\
\hline & 2 & 24 & 1 & 23 & 1 & 49 & & & \\
\hline & 3 & 19 & 7 & 29 & 0 & 55 & & & \\
\hline & 4 & 14 & 6 & 20 & 0 & 40 & & & \\
\hline \multicolumn{2}{|l|}{ Total } & 67 & 16 & 76 & 1 & 160 & & $12.787^{\mathrm{a}}$ & 0.385 \\
\hline
\end{tabular}

Table 7: BPE versus ethnicity, level of qualification and level of employment.

\section{Discussion}

This study sought to describe knowledge of the periodontal status of pregnant women in Trinidad along with their perceived oral health status, practices and knowledge. No previous data exists for this population.

Less than one quarter (20.1\%) of participants rated their oral health as above average in this study (37.7\%) as fair or average. This finding may suggest there exist a level of unmet dental and oral health need among pregnant mothers in Trinidad. Further evidence of unmet need among this group was exhibited by the finding of higher levels of toothache (34.3\%) and cavities (65.2\%). These findings were higher than those found in similar study [8] with $16.9 \%$ (toothache) and $41.5 \%$ (cavities). In contrast to the partici- pants perceptions of their own oral health, the majority, (68.9\%) felt that oral health is extremely important when compared to general health. This finding is higher than that of another study that reported only $46.5 \%$ [8]. Despite this, our study showed that over $90 \%$ of participants did not attend the dentist for routine care and nearly $75 \%$ attended only when they had a problem. This is consistent with other documented evidence where it was found that pregnant women are hesitant to take up dental treatment [17-19]. These findings could be due to misinformation about the relationship between pregnancy and dental procedures or could suggest the existence of other potential barriers to care among this cohort such as cost, which nearly $55 \%$ said in this study was a barrier. This is agreement with other studies documenting cost as a significant barrier for accessing care $[12,20,21]$. 
In the UK under the National Health Service, dental treatment is free for pregnant women and up to one year post- partum. Yet a study on immigrant mothers in North London found attendance rates of 32\% [22]. Other studies done in rural communities in India [23] and Nigeria [24] also found very low attendance for dental treatment during pregnancy. Currently dental services in Trinidad can be accessed privately (fee per item service) or free of cost through government funded public health facilities. However, no documentary evidence is currently available to identify the barriers to accessing care at these facilities.

Also, almost half of the participants were concerned about safety during dental treatment and that could potentially affect health seeking behaviors among this group. This concern found in the Trinidad cohort is similar to the USA [12] and Australia [8,10]. Additionally, of concern was the finding that $37.3 \%$ of pregnant women felt dental care should be avoided during pregnancy. This misconception has been reported in other studies around the world [18,25-27]. The majority also had the false impression that cavities could not be spread from the mother to the baby's mouth and nearly three-quarters did not believe that a mother's poor oral health could contribute to low birth weight (LBW) babies. Additionally, almost one third (32.3\%) did not believe that sleeping with a bottle containing formula could cause holes on a baby's teeth. Safety concerns, avoidance of care and the reported misconceptions can be addressed by improving awareness of oral health during pregnancy in Trinidad through education and health promotion.

In this study most participants did have good oral health practices with over three-quarters reporting that they brushed their teeth twice daily and the majority reporting the use of fluoridated toothpaste This is similar to other studies $[8,20,21]$. However, despite the positive reported oral health behaviors, nearly $60 \%$ of pregnant mothers had some form of periodontitis. Similar studies have found high prevalence of periodontal disease in pregnant women such as Gupta and Acharya, [23] (95\%), Miyazaki., et al. [28] (95\%) and Jago., et al. [29] (84\%) and more recently Gonzalez-Jaranay., et $a l$. [30]. Such findings may indicate that dental health education inclusive of proper oral hygiene techniques as well as routine dental hygiene procedures are required for this group.

Another important finding of this study was that $8.1 \%$ of the expectant mothers were smokers. This finding is of concern as smoking in pregnancy is associated with poor pregnancy outcomes $[31,32]$. The literature shows that internationally, large numbers of pregnant women smoke, with rates between $12 \%$ and $22 \%$ in high-income countries [33]. There is an important need to promote smoking cessation not only in the general population but also in this at risk group as well.

Limitations of this study may include the oral examination protocol used might under estimate the prevalence of oral health problems. The literature has demonstrated that partial examination protocols underestimate the amount and this estimate bias varies according to site, type, number of sites per tooth and number of quadrants recorded [34]. Other limitations of this study include the periodontal health status of this population may not be as evenly distributed in the general population as it was in this convenience sample. Also, there may have been bias in the self-reported oral health assessment and this study did not determine the number, if any, of patients with gestational diabetes, which may contribute to the level of disease reported.

\section{Conclusion}

The findings reported in this study suggest important gaps and misconceptions in oral health knowledge and practices of pregnant women in Trinidad. This may have implications for the general and oral health of their children and indicate the need for oral health promotion among this group. The prevalence of periodontitis was found to be high and related to age and ethnicity. Understanding oral health needs of pregnant women can guide oral health promotion and delivery of preventive care and potentially improve pregnancy outcomes.

\section{Acknowledgements}

We acknowledge all the pregnant women who participated in the study from the Mount Hope Maternity Hospital in Trinidad and the staff that facilitated our data collection on site. We thank Dr. Wayne Haqq and Dr. Randall Gooding from Mount Hope Maternity Hospital for facilitating the study.

\section{Conflict of Interest}

The authors declare that they have no conflict of interests or financial interests.

\section{Bibliography}

1. Silk H., et al. "Oral Health during pregnancy". American Family Physician 77 (2008): 1139-1144.

2. Laine MR. "Effect of pregnancy on periodontal and dental health". Acta Odontologica Scandinavica 60 (2002): 257-267. 
3. Papapanou PN. "Periodontal diseases: epidemiology". Annuals of Periodontology 11 (1996): 1-36.

4. Jain $\mathrm{K}$ and Kaur H. "Prevalence of oral lesions and measurement of salivary $\mathrm{pH}$ in the different trimesters of pregnancy". Singapore Medical Journal 56 (2015): 53-57.

5. Balkaran R., et al. "A Preliminary Investigation of Periodontal Disease and Diabetes in Trinidad". West Indian Medical Journal 60 (2011): 86.

6. George A., et al. "Periodontal treatment during pregnancy and birth out comes: a meta-analysis of randomised trials". International Journal of Evidence-Based Healthcare 9 (2011): 122147.

7. Shub A., et al. "Maternal periodontal disease and perinatal mortality". Australian and New Zealand Journal of Obstetrics and Gynaecology 49 (2009): 130-136.

8. George A., et al. "The oral health status, practices and knowledge of pregnant women in south-western Sydney". Australian Dental Journal 58 (2013): 26-33.

9. Harris J. "The forgotten system during pregnancy: Women and Oral health". International Journal of Childbirth Education 32 (2017): 1-50.

10. George A., et al. "Promoting oral health during pregnancy: current evidence and implications for Australian midwives". Journal of Clinical Nursing 19 (2010): 3324-3333.

11. American Academy of Paediatric Dentistry. Guideline on Perinatal Oral Health care, Chicago: AAPD (2011).

12. California Dental Association. Oral Health during pregnancy and early childhood. Evidence based guidelines for Health Professionals, CDA (2010).

13. Dharmashree S and Kumar M. "Oral health status of 300 pregnant women attending antenatal clinics of Vishakhapatnam City-One year descriptive cross-sectional study". International Journal of Contemporary Medical Research 5 (2018): 1-6.

14. Silness J and Löe H. "Periodontal disease in pregnancy. Correlation between oral hygiene and periodontal condition". Acta Odontologica Scandinavica 22 (1964): 112-135.

15. Corbet EF. "Oral Diagnosis and treatment planning: part 3. Periodontal disease and assessment of risk". British Dental Journal 213 (2012) :111-121.

16. British Society of Periodontology. Basic Periodontal examination (2011).
17. Al-Habashneh R., et al. "Factors related to utilization of dental services during pregnancy". Journal of Clinical Periodontology 32 (2005): 815-821.

18. Saddki N., et al. "Factors associated with dental visit and barriers to utilisation of oral health care services in a sample of antenatal mothers in Hospital University Sains Malaysia". BMS Public health 10 (2010): 75.

19. Erchick DJ., et al. "Oral hygiene, prevalence of gingivitis, and associated risk factors among pregnant women in Sarlahi District, Nepal". BMC Oral Health 19 (2019): 2.

20. Thomas NJ., et al. "Oral and health care practice in pregnant women in Australia: a postnatal survey". BMC Pregnancy Child Birth 8 (2008): 13-20.

21. Keirse MJNC and Plutzer K. "Women's attitudes to and perceptions of oral health and dental care during pregnancy". Journal of Perinatal Medicine 38 (2010): 3-8.

22. Hullah E., et al. "Self-reported oral hygiene habits, dental attendance, and attitudes to dentistry during pregnancy in a sample of immigrant women in North London". Archives of Gynecology and Obstetrics 277 (2008): 405-409.

23. Gupta R and Acharya AK. "Oral health status and treatment needs among pregnant women of Raichur District, India: A population based cross-sectional study". Scientifica (2016): 8.

24. Lasisi TJ., et al. "Pattern of oral health among a population of pregnant women in Southwestern Nigeria". Archives of Basic Applied Medicine 6 (2018): 99-103.

25. Dinas K., et al. "Pregnancy and oral health: utilization of dental services during pregnancy in northern Greece". Acta Obstetricia et Gynecologica Scandinavica 86 (2007): 938-944.

26. Mangskau KA and Arrindell B. "Pregnancy and oral health; utilization of the oral health care system by pregnant women in North Dakota". Northwest Dentistry 75 (1996): 23-28.

27. Lydon-Rochelle MT., et al. "Dental Care Use and Self-Reported Dental Problems in Relation to Pregnancy". American Journal of Public Health 94 (2004): 765-771.

28. Miyazaki H., et al. "Periodontal condition of pregnant women assessed by CPITN". Journal of Clinical Periodontology 18 (1991): 751-754.

29. Jago JD., et al. "Dental status of pregnant women attending a Brisbane maternity hospital". Community Dentistry and Oral Epidemiology 12 (1984): 398-401. 
30. Gonzalez-Jaranay M., et al. "Periodontal status during pregnancy and post-partum". PLoS One 12 (2017) e0178234.

31. Cnattingius S. "The epidemiology of smoking during pregnancy: smoking prevalence, maternal characteristics, and pregnancy outcomes". Nicotine and Tobacco Research 6 (2004): 125-140.

32. Andriani $\mathrm{H}$ and Kuo HW. "Adverse effects of parental smoking during pregnancy in urban and rural areas". BMC Pregnancy Childbirth 14 (2014): 414.

33. Tong VT., et al. "Trends in smoking before, during, and after pregnancy-pregnancy risk assessment monitoring system, United States, 40 sites, 2000-2010". Morbidity and Mortality Weekly Report: Surveillance 62 (2013): 1-19.

34. Albandar JM. "Underestimation of periodontitis in NHANES surveys". Journal of Clinical Periodontology 82 (2011): 337341.

\section{Assets from publication with us}

- Prompt Acknowledgement after receiving the article

- Thorough Double blinded peer review

- Rapid Publication

- Issue of Publication Certificate

- High visibility of your Published work

Website: www.actascientific.com/

Submit Article: www.actascientific.com/submission.php

Email us: editor@actascientific.com

Contact us: +919182824667 